\title{
PROTEINOGRAMA DO LIQUIDO CEFALORRAQUEANO NA LEPRA LEPROMATOSA
}

\author{
WILSON BROTTO * \\ A. SPINA-FranÇA **
}

Em trabalho anterior foram registradas alterações do proteinograma do líquido cefalorraqueano (LCR) de pacientes com lepra $\%$. As alterações encontradas foram discretas e puderam ser relacionadas a certos aspectos clínicos e biológicos da doença. Entre as alterações descritas no proteinograma do LCR salientam-se a ocorrência de aumento do teor de albumina em casos recentes da forma inespecífica da doença, o aumento do teor de $\beta$ globulina em pacientes com lepra tuberculóide e o de $\gamma$-globulina em pacientes com lepra lepromatosa.

O aumento de $\gamma$-globulina no LCR nos casos de lepra lepromatosa parecia secundário ao aumento dessa fração no sangue. Entretanto, o número de pacientes com essa forma da doença era pequeno, não permitindo maiores conclusōes.

No presente trabalho é analisado o proteinograma do LCR de maior série de pacientes com lepra lepromatosa para avaliar a freqüência e a intensidade com que ocorre o aumento do teor de $\gamma$-globulina no LCR nessa forma clínica da doença e suas relações com o aumento dessa fração no sôro.

\section{MATERIAL E METODOS}

O estudo é baseado na análise dos dados referentes a 45 pacientes acometidos de lepra, todos portadores da forma lepromatosa. A reação de Mitsuda foi negativa em todos. Em 6 casos a pesquisa de bacilos álcool-resistentes foi positiva: em 4 a presença de bacilos foi demonstrada em lesão cutânea (casos 21, 22, 25 e 27) e, em dois, na lesão cutãnea e no muco nasal (casos 24 e 29). Quarenta pacientes eram brancos, um era prêto (caso 41) e 4 eram pardos (casos 4, 16, 20 e 26). O sexo e a idade dos pacientes são referidos na tabela 1 , bem como o tempo de evolução da doença.

Para cada caso foi estudado o proteinograma de uma amostra de LCR colhida na cisterna magna (punção suboccipital); sem alterações quanto ao aspecto, côr e citologia; as reações de fixação do complemento para sifilis e para cisticercose foram negativas em tôdas as amostras. Para fins comparativos, foi estudado o proteinograma do sôro sangüineo (sôro de cada paciente por ocasião da colheita do LCR.

* Neurologista do Departamento de Profilaxia da Lepra do Estado de São Paulo.

** Assistente da Clínica Neurológica da Fac. Med. da Univ. de São Paulo (Prof. Adherbal Tolosa). 
A concentração protêica total foi determinada, no LCR, pelo método turbidimétrico do ácido tricloracético $\epsilon$, no sôro, pelo do biureto. As frações protêicas foram estudadas, no LCR e no sôro, por eletroforese em papel. As técnicas empregadas nas determinaçōes foram descritas anteriormente ${ }^{2}$, bem como os valôres normais considerados na interpretação dos dados obtidos ${ }^{3}$.

\begin{tabular}{|c|c|c|c|c|c|c|c|}
\hline Caso & Sexo & $\begin{array}{l}\text { Idade } \\
\text { (anos) }\end{array}$ & $\begin{array}{l}\text { Tempo de } \\
\text { evolucúo } \\
\quad(\text { anos) }\end{array}$ & Caso & Sexo & $\begin{array}{l}\text { Idade } \\
\text { (anos) }\end{array}$ & $\begin{array}{c}\text { Tempo de } \\
\text { evolução } \\
\text { (anos) }\end{array}$ \\
\hline 1 & $\mathrm{~m}$ & 59 & 17 & 24 & $\mathrm{~m}$ & 50 & 8 \\
\hline 2 & $\mathrm{~m}$ & 57 & 15 & 25 & $\mathrm{~m}$ & 45 & 9 \\
\hline 3 & $f$ & 35 & 20 & 26 & $f$ & 31 & 10 \\
\hline 4 & $\mathrm{~m}$ & 44 & 20 & 27 & f & 24 & 8 \\
\hline 5 & $\mathrm{~m}$ & 64 & 19 & 28 & $f$ & 36 & 20 \\
\hline 6 & $\mathrm{~m}$ & 57 & 20 & 29 & $\mathrm{~m}$ & 60 & 24 \\
\hline 7 & $f$ & 40 & 8 & 30 & $f$ & 49 & 30 \\
\hline 8 & f & 41 & 21 & 31 & f & 27 & 16 \\
\hline 9 & $f$ & 52 & 20 & 32 & $\mathrm{~m}$ & 43 & 31 \\
\hline 10 & $\mathrm{~m}$ & 53 & 10 & 33 & $\mathrm{~m}$ & 57 & 5 \\
\hline 11 & f & 70 & 35 & 34 & f & 35 & 17 \\
\hline 12 & $\mathrm{f}$ & 65 & 40 & 35 & $\mathrm{~m}$ & 30 & 9 \\
\hline 13 & f & 38 & 3 & 36 & $\mathrm{~m}$ & 32 & 19 \\
\hline 14 & $f$ & 48 & 32 & 37 & $\mathrm{~m}$ & 39 & 14 \\
\hline 15 & $f$ & 41 & 27 & 38 & $\mathrm{f}$ & 37 & 15 \\
\hline 16 & $\mathrm{~m}$ & 35 & 4 & 39 & $\mathrm{~m}$ & 40 & 29 \\
\hline 17 & $\mathrm{f}$ & 43 & 29 & 40 & $\mathrm{~m}$ & 38 & 12 \\
\hline 18 & $\mathrm{~m}$ & 28 & 5 & 41 & $\mathrm{~m}$ & 31 & 8 \\
\hline 19 & $m$ & 54 & 16 & 42 & $\mathrm{~m}$ & 46 & 16 \\
\hline 20 & f & 46 & $1 \tilde{5}$ & 43 & $\mathrm{f}$ & 54 & 23 \\
\hline 21 & $\mathrm{~m}$ & 37 & 10 & 44 & $\mathrm{f}$ & 37 & 1 \\
\hline 22 & $\mathrm{f}$ & 34 & 6 & 45 & $\mathrm{~m}$ & 35 & 15 \\
\hline 23 & $\mathrm{f}$ & 53 & 18 & & & & \\
\hline
\end{tabular}

Tabela 1 - Sexo, idade e tempo de evalução da doença dos 45 casos.

\section{RESULTADOS}

Os resultados referentes ao proteinograma do LCR e do sôro são apresentados na tabela 2 . 


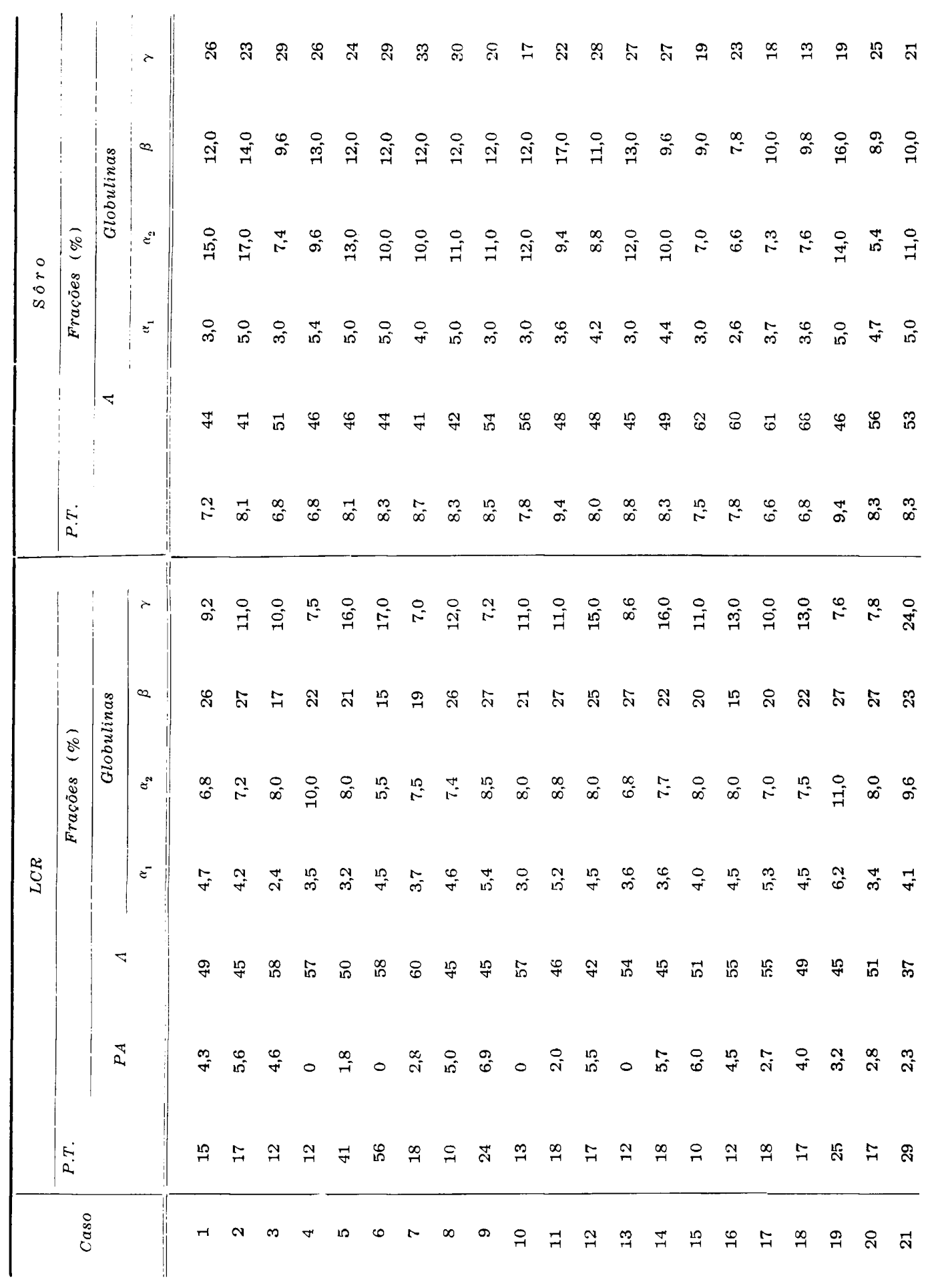




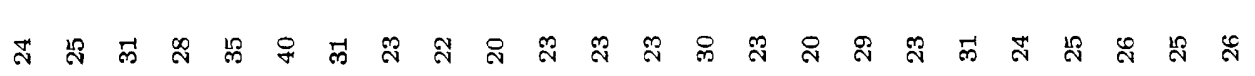

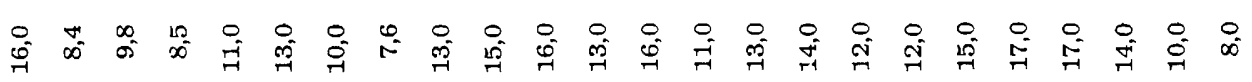

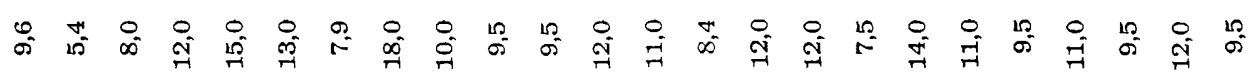

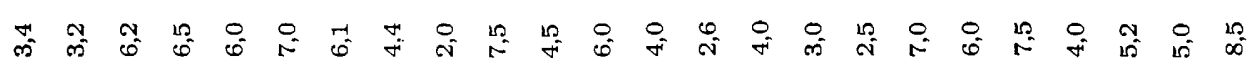

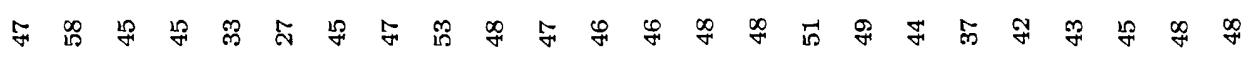

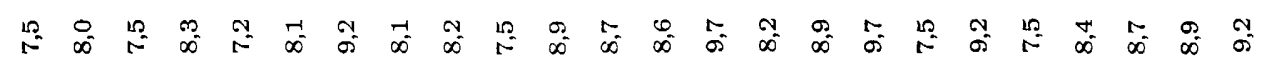

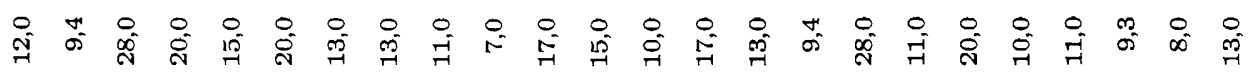

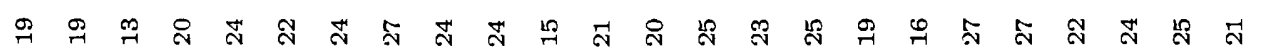

IF 용 $\begin{gathered}\infty \\ \infty\end{gathered}$

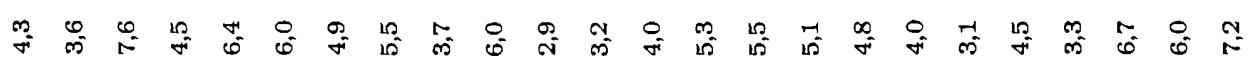

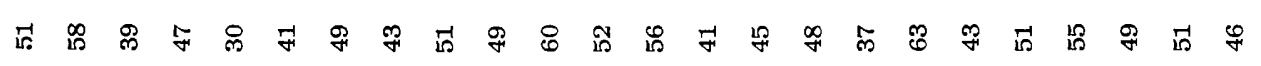

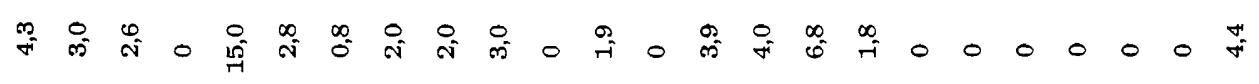

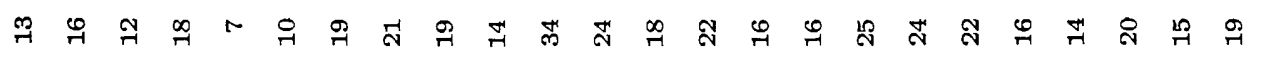

ส

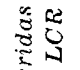


Proteinograma do sôro - A alteração mais freqüente do proteinograma do sôro foi representada pelo aumento da concentração de $\gamma$-globulina ( 37 casos). As taxas desta fração protêica eram anormais em 8 pacientes (casos 9, 10,15, 17, 18, 21, 31 e 39). O aumento da concentração de $\gamma$-globulina no sôro era acompanhado da diminuição da taxa de albumina em dois pacientes (casos 26 e 27), de aumento das demais globulinas em um (caso 19), de aumento da concentração da globulina $\alpha_{1}$ em 8 (casos 24, 25, 27, 28, 33, 43, 44 e 45), da globulina $\alpha_{2}$ em dois (casos 2 e 29) das globulinas $\alpha_{1}$ e $\beta$ em dois ( $\operatorname{cosos} 40$ e 41) e da $\beta$-globulina em 4 (casos 11, 32,34 e 42). Em dois pacientes foi verificado aumento isolado da globulina $\alpha_{1}$ (casos 31 e 39).

Proteinograma do $L C R$ - A concentração protêica total das amostras estudadas era normal em 42 casos. Nos três restantes estava aumentada (casos 5,6 e 32 ); os aumentos verificados eram discretos, sendo de $56 \mathrm{mg} / 100 \mathrm{ml}$ a maior taxa encontrada.

No perfil eletroforético foi verificada a ocorrência de aumento do percentual de $\gamma$-globulina em 14 pacientes (casos $5,6,12,14,21,24,25,26,27,32,33,35,38$ e 40). Nos demais o perfil era normal, com exceção de dois casos; em um havia discreto aumento do teor de albumina (caso 39) e, em outro, pequena diminuição de $a_{1}$-globulina (caso 3 ).

O aumento referido para o teor de $\gamma$-globulina foi discreto na maioria dos casos; sòmente em três ultrapassiva o teor de $20 \%$ (casos 21, 24 e 38). O aumento do percentual dessa globulina representava a única alteração do perfil eletroforético em 7 casos; acompanhava-se de diminuição do teor de albumina nos demais (casos $12,21,24,26,27,35$ e 38). Em um dêstes havia também diminuição do percentual de $\beta$-globulina (caso 24). Em 13 pacientes a fração pré-albumina se achava ausente (casos $4,6,10,13,25,32,34,39,40,41,42,43$ e 44).

\section{COMENTARIOS}

Proteinograma do sôro -- Alteraçōes nos teores globulínicos são freqüentes no sôro de pacientes com lepra ${ }^{5}$. Em geral, as concentrações das diversas globulinas tendem a apresentar-se acima da média normal (quadro 1). Essa tendência é mais pronunciada em relação às globulinas $\alpha$ e $\gamma$. As concentraçōes da última assumem freqüentemente niveis patológicos. Assim, em 37 dos casos estudados, foi verificado o aumento dessa fração protêica.

A tendência ao aumento das globulinas do sôro leva a que, no perfil eletroforético, ocorra predomínio do percentual das globulinas sôbre o de albumina.

Relação entre o proteinograma do LCR e o do sôro - As alterações do proteinograma do sôro não costumam refletir-se no proteinograma do LCR. Assim, nos casos estudados o proteinograma do LCR era normal ou apresentava alterações discretas. Essa diferença de comportamento que ocorre na lepra acarreta modificações das relações normalmente observadas entre os percentuais das diferentes frações protêicas no LCR e no sôro; em publicação anterior ${ }^{5}$ foram analisadas as peculiaridades dessas relações na lepra. Na presente série de casos os achados são semelhantes (quadro 2), caracterizando-se por tendência a ser maior que a normal a relação entre os teores de albumina e de $\beta$-globulina e menor a das $\alpha$-globulinas. Para a relação entre os percentuais de $\gamma$-globulina não foi observada tendência definida: em 24 casos a relação era menor que 0,5 e em 21 , maior, tendência também observada anteriormente 5 . 


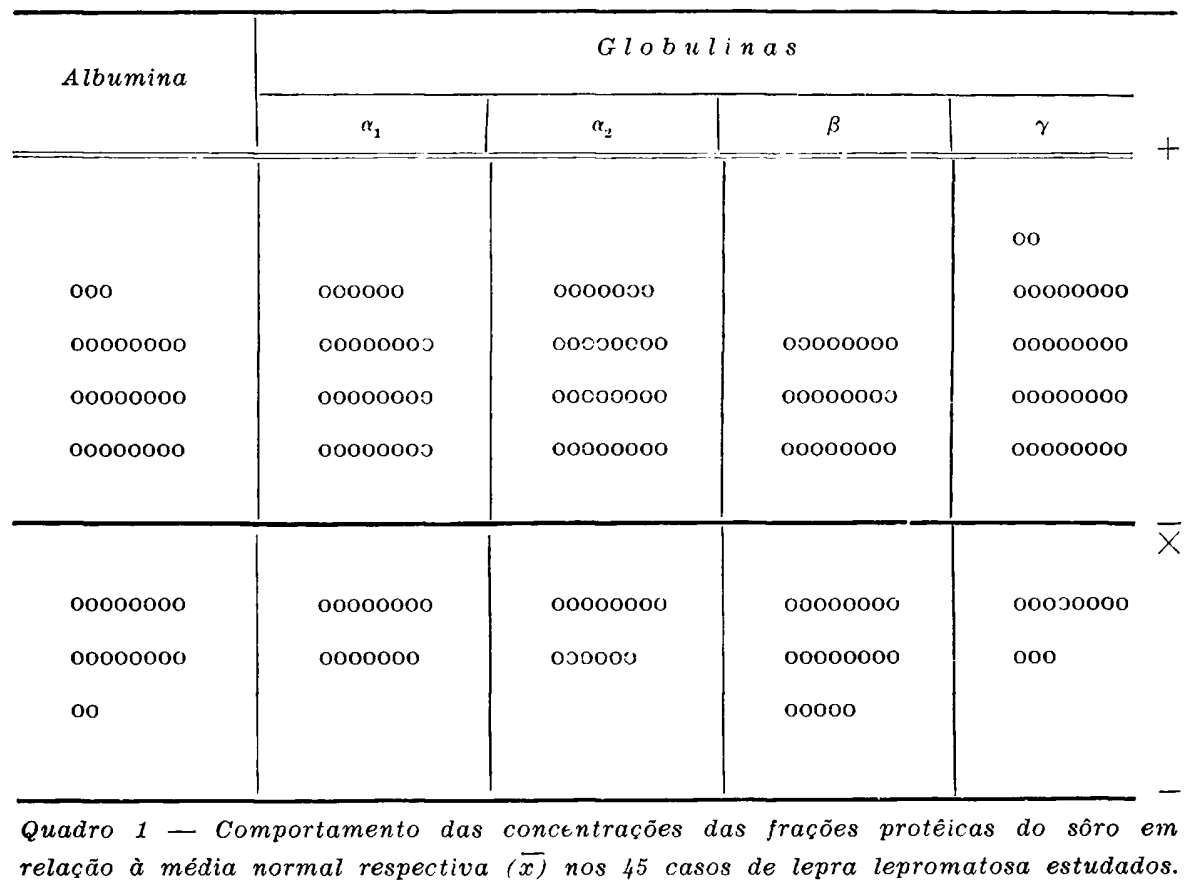

\begin{tabular}{|c|c|c|c|}
\hline \multirow{2}{*}{ Albumina } & \multicolumn{3}{|c|}{ Globulinas } \\
\hline & $\alpha$ & $\beta$ & $\gamma$ \\
\hline 0000000 & & 00000 & \\
\hline oooooooo & & 00000000 & ooooo \\
\hline 00000000 & 000000 & oooooooo & 00000000 \\
\hline 00000000 & 00000000 & 00000000 & 00000000 \\
\hline 00000000 & oooooooo & 00000000 & oooooooo \\
\hline oooooo & 00000000 & oooooono & 00000000 \\
\hline & 00000000 & & 00000000 \\
\hline & 0000000 & & \\
\hline
\end{tabular}

Quadro 2 - Comportamento da relacão entre o percentual das fracóes protêicas no LCR e no sôro, em relação à média normal respectiva $(\bar{x})$, nos 45 casos de lepra lepromatosa estudados. 
A correlação entre a concentração protêica total do LCR e a do sangue é representada por valor não significativo $(r=0,27)$, para os 45 casos estudados.

Proteinograma do $L C R$ - O aumento de $\gamma$-globulina representou a alteração mais comum do perfil eletroforético do LCR, tendo ocorrido em cêrca de um têrço dos pacientes (14 casos). A ocorrência de aumento de $\gamma$-globulina no LCR não guardava relação com a idade e o sexo dos pacientes nem com o tempo de evolução da doença, embora não tivesse sido observado entre os pacientes cuja doença evoluía por tempo menor ou igual a 5 anos.

O aumento do teor de $\gamma$-globulina no LCR ocorreu de modo mais freqüente entre os pacientes com maiores taxas de proteínas totais no LCR. Assim, ocorreu apenas em 6 dos 33 casos cuja proteinorraquia total correspondia a valôres iguais ou menores que $20 \mathrm{mg} / 100 \mathrm{ml}$ e em 5 dos 9 casos em que se achava entre 21 e $30 \mathrm{mg} / 100 \mathrm{ml}$. Nos 3 casos em que a concentração protêica total estava aumentada foi verificado aumento do teor de $\gamma$-globulina. As médias representativas dos perfis eletroforéticos para grupos estabelecidos de acôrdo com a taxa de proteínas totais da amostra, permitem ter idéia do mesmo fato (quadro 3 ).

\begin{tabular}{l|c|c|c|c|c|c|c}
\hline $\begin{array}{c}\text { Proteinas } \\
\text { totais }\end{array}$ & $n$ & $\begin{array}{c}\text { Pré- } \\
\text { albumina }\end{array}$ & $\begin{array}{c}\text { Albumi- } \\
n a\end{array}$ & \multicolumn{4}{|c}{ Globulinas } \\
\cline { 3 - 7 } 12 & 9 & 4,50 & 47,8 & 4,73 & 8,07 & 20,7 & 13,9 \\
$13-17$ & 12 & 2,91 & 50,4 & 4,58 & 8,26 & 23,2 & 10,7 \\
$17-21$ & 13 & 2,37 & 49,5 & 4,76 & 8,44 & 23,2 & 11,7 \\
$22-30$ & 8 & 2,50 & 45,4 & 4,51 & 8,26 & 23,1 & 16,2 \\
31 ou mais & 3 & 0,60 & 56,0 & 3,90 & 6,20 & 17,0 & 16,7 \\
\hline
\end{tabular}

Quadro 3 - Perfis eletroforéticos médios obtidos pela distribuição dos casos estudados segundo a concentração protêica total. Os grupos foram estabelecidos em relação à média e ao desvio padrão da proteinorraquia total normal 4 . Legenda: $\mathrm{n}$, número de casos do grupo. Proteinas totais referidas em $\mathrm{mg} / 100 \mathrm{ml}$; frações protêicas referidas em percentual.

Há vários dados que levam a admitir que o aumento de $\gamma$-globulina no LCR seja secundário ao aumento dessa globulina no sôro .Entre êles destaca-se o fato de os aumentos verificados no teor dessa globulina terem sido discretos, não ultrapassando $20 \%$ na maioria dos pacientes (11 casos). Aumentos dessa ordem no teor de globulina no LCR são geralmente observados como conseqüência de aumento dessa fração no sangue ${ }^{1}$. De fato, a freqüência em que ocorreu o aumento de $\gamma$-globulina no LCR foi maior 
entre os pacientes em cujo sôro foi observado aumento dessa fração protêica (quadro 4). Outro dado favorável à hipótese de o aumento do teor de $\gamma$-globulina no LCR ser secundário ao aumento dessa fração no sôro é representado pelo fato de a relação $\mathrm{LCR} /$ sôro do teor dessa globulina não ter sofrido modificações na maioria dos 14 casos com aumento de $\gamma$-globulina no LCR. Assim os valôres dessa relação eram normais (de 0,4 a 0,6 ) em 7 casos e estavam levemente aumentados em 4 (0,61 a 0,75). Sòmente nos 3 casos com aumento de $\gamma$-globulina no LCR superior a $20 \%$ os valôres dessa relação eram maiores, oscilando ao redor da unidade.

\begin{tabular}{c|c|c}
\hline LCR & Normal & Aumentada \\
\hline Normat & 7 & 24 \\
\hline Aumentada & 1 & 13 \\
\hline
\end{tabular}

Quadro 4 - Distribuição dos 45 casos de lepra lepromatosa estudados segundo o comportamento da $\gamma$-globulina no LCR e no sôro.

\section{RESUMO E CONCLUSÓES}

Foi estudado o proteinograma do LCR e o do sôro de 45 pacientes com lepra lepromatosa.

A alteração principal encontrada no proteinograma do LCR foi o aumento do teor de $\gamma$-globulina, verificado em cêrca de um têrço dos pacientes (14 casos). O aumento dessa globulina ocorreu de modo mais freqüente nos casos com taxa de proteinas totais maior. $O$ aumento de $\gamma$-globulina no LCR não guardava relações com o sexo ou a idade dos pacientes, nem com o tempo de evolução, embora não tivesse sido registrado entre os casos cuja doença evoluía há 5 anos ou menos.

A análise do material apresentado sugere que o aumento do teor de $\gamma$-globulina que pode ocorrer na lepra lepromatosa seja secundário ao aumento dessa globulina no sangue. Entre os dados favoráveis a essa hipótese são apresentados os fatos de: os aumentos observados no teor dessa fração terem sido discretos na maioria das vêzes (11 casos); de os aumentos dessa globulina no LCR terem ocorrido na maioria das vêzes em casos com aumento dessa globulina no sôro e o de terem ocorrido sem que se alterasse a relação LCR/sôro do teor dessa globulina na maioria dos casos. 


\section{SUMMARY}

Cerebrospinal fluid proteins in leprosy. A study concerning to the lepromatous form of the disease.

The study is based on the observations concerning to 45 patients with leprcmatcus Jeprosy. The test of Mitsuda was negative in all of them. Alcchol-acid fast bacilli were found to be present in 6 cases in cutaneous lesions and/or in nasal cavity.

The study of the CSF proteins comprised the determination of the total protein content and the analysis of the proteins fractions, the latter by papel strip electrophoresis. For each patient it was studied one sample of CSF, collected from the cisterna magna and normal concerning to its physics and cytologic properties; complement fixation tests for syphilis and cysticercosis were negative in all samples. For comparison purposes other data were studied: 1 . the total protein content of blood serum and its protein fractions, the latter by paper strip electrophoresis also; 2 . the age of the patients; 3 . the probable time of disease.

Results are presented in the table 2. The total concentration of CSF proteins was normal in 42 patients; it was slightly increased in three cases. Changes in electrophoretic pattern of CSF proteins were verified in several cases. The most frequent change was the increase of the $\gamma$-globulin fraction (14 cases). Its occurrence in this form of the disease was related in a previous former study; the present data confirm such observation.

The data discussed in this study show that the increase in the CSF $\gamma^{-g l o b u l i n}$ is probably related to change in the protein pattern of blood serum. It seems to be secondary to the increase of the $\gamma$-globulin fraction in the latter.

\section{REFERENCIAS}

1. MATIAR, H.; SCHMIDT, C. - Der Erhöhung der Gamma-globulin im Liquor. Deutsche Ztschr. P. Nervenh., 178:300-312 (outubro) 1958. 2. SPINA-FRANCCA, A. - Eletroforese em papel das proteínas do líquido cefalorraqueano: Técnica. Arq. Neuro-Psiquiat., 16:236-242 (setembro) 1958. 3. SPINA-FRANÇA, A. - Eletroforese em papel das proteinas do liquido cefalorraqueano: Valôres normais. Arq. NeuroPsiquiat., 18:19-28 (marȩo) 1960. 4. SPINA-FRANÇA, A.; AMAR, I. - Valôres normais da concentração protêica do líquido cefalorraqueano: variaçōes ligadas ao local de colheita da amostra. Arq. Neuro-Psiquiat., 19:220-225 (setembro) 1961. 5. SPINAFRANÇA, A.; BROTTO, W. - Proteinograma do líquido cefalorraqueano na lepra. Arq. Neuro-Psiquiat., 20:279-288 (dezembro) 1962.

Clínica Neurológica - Faculdade de Medicina da USP - Caixa Postal 3461 São Paulo, SP - Brasil. 